\title{
Technology Strategy for Construction Automation
}

\author{
Keith D. Hampson and C.B. Tatum ${ }^{\mathrm{b}}$ \\ ${ }^{\text {a }}$ School of Construction Management, Queensland University of Technology, Brisbane, AUSTRALIA \\ ${ }^{b}$ Department of Civil Engineering, Stanford University, Palo Alto, California, USA
}

\begin{abstract}
Automation technology can provide construction firms with a number of competitive advantages. Technology strategy guides a firm's approach to all technology, including automation. A more formal approach to the concept of technology strategy can benefit the construction manager in his efforts to remain competitive in increasingly hostile markets. This paper recommends consideration of five specific dimensions of technology strategy within the overall parameters of market conditions, firm capabilities and stage of technology evolution. Examples of the application of this framework in the formulation of technology strategy are provided for CAD applications, coordinated positioning technology and advanced falsework and formwork mechanization to support construction field operations. Results from this continuing line of research can assist managers in making complex and difficult decisions regarding their approach to new construction technology and benefit future researchers by providing new tools for analysis.
\end{abstract}

\section{INTRODUCTION}

The increasing technical feasibility of automation for construction brings major opportunities and requirements to develop approaches for the most beneficial use of this technology in firms. Automation technology will compete with human resources and other technologies for investment of scarce resources to continuously improve performance in construction firms. What approaches will bring the most improvement in the competitive performance of individual firms?

Whether explicitly stated or implicitly defined by managers' decisions and actions, the technology strategy for a firm guides the approach to all technology, including automation. Similar to human resource, finance, or marketing strategy, technology strategy is one of the functional strategies that support the competitive and corporate strategies of a firm. The purpose of this paper is to describe the elements of technology strategy for construction firms and apply these elements to the consideration of automation.

It is based on an ongoing investigation of technology strategy and competitive performance in infrastructure construction. This research will increase understanding of technology strategy and its relationship to competitive performance in construction, and support actions by construction researchers and professionals to improve the performance of construction firms through more effective use of technology. The following specific objectives structure this investigation: provide elements and measures to classify technology 
strategy in the construction industry, increase understanding of how technology strategy relates to competitive performance for infrastructure construction, and provide recommendations and techniques for analysis of technological alternatives and use of advanced technology to improve the competitive performance of construction firms.

The classification for technology strategy used in this research consists of five key dimensions: competitive positioning, sourcing of technology, technological scope, technical depth, and organizational fit. Competitive positioning is the relative command of specific technologies and monitoring alternative technologies potentially available from other sources. Sourcing is the acquisition of explicit (hardware) and implicit (knowledge) technologies. The scope dimension identifies the core and peripheral technologies for the firm. Depth highlights relative level of investment and extent of technical capabilities. Organizational fit includes the match of reward systems with technological objectives, the flow of technical information, and the matching of capabilities to project requirements. Each of these dimensions guides the construction manager's approach to the acquisition and implementation of technology.

This paper describes the application of this classification for technology strategy to construction automation. Since the concepts of technology strategy and automation technology are new to construction firms, this paper describes the process of formulating technology strategy and possible approaches for each of the dimensions related to construction automation and mechanization. This analysis of technology strategy for automation includes examples of $\mathrm{CAD}$ application to support construction and positioning technology and mechanization to support field operations. The conclusions highlight the steps and options in formulating technology strategy, and the benefits for competitive performance of construction firms.

\section{TECHNOLOGY STRATEGY}

\subsection{Technology and Strategy}

For this research we define construction technology as the combination of resources, processes and conditions that produce a constructed product. A resource can be either materials and permanent equipment or a temporary addition by construction. Construction processes are the methods and tasks needed to build a constructed product. Project requirements and site characteristics are the major conditions of construction technology (Tatum, 1988).

A strategy is a unified, comprehensive and integrated plan relating the strategic advantages of the firm to the challenges of the environment. It is designed to achieve the basic objectives of the enterprise (Glueck, 1980). Chandler $(1962, \mathrm{p} 13)$ defined strategy as "the determination of the basic long-term goals and objectives of the enterprise and the adoption of courses of action and the allocation of resources necessary for carrying out these goals". To define technology strategy, Adler (1989) adapted Andrew's (1980) definition of business strategy: technology strategy is a pattern of decisions that sets the technological goals and the principle technological means for achieving both those technological goals and the business goals of the organization.

\subsection{Elements of Technology Strategy}

A range of determinants for technology strategy provided by others (Ansoff and Stewart, 1967; Freeman, 1982; Miles and Snow, 1978; Maidique and Patch, 1988; Burgelman and Rosenbloom, 1989; Malekzadeh et al, 1989) has been reviewed with the 
objective of selecting one set of parameters that ensures conceptual completeness, but avoids unnecessary duplication. The following technology strategy dimensions synthesizes the background:

- competitive positioning refers to the role that technology plays in establishing generic competitive advantage or how product technology, process technology and technical support capabilities are used to achieve cost leadership or differentiation (Porter, 1985). Maidique and Patch (1988, p241) raise the managerial question of "what new technologies to add to the firm's core set of technological skills?" Three factors that guide strategy in an important technology are: sustainability of the technology lead, first-mover advantages, and first-mover disadvantages (Porter, 1985).

$\circ$ sourcing of technology incorporates the dual (but overlapping) concepts of Burgelman and Rosenbloom's "Technology and the Value Chain" and the Malekzadeh et al "Sources of Technological Capability". To remain competitive a firm must structure ways to acquire certain value-creating technologies, i.e.. the develop or buy argument. This decision to acquire new technology is, as described by Rosenberg et al (1990, p22), "inescapably an investment decision".

- scope of technology strategy describes the set of product and process technologies in which the business unit has invested combined with an assessment of the maturity of the technologies (Malekzadeh et al, 1989). No firm can hope to operate on the frontiers of all technologies relevant to its operations. The set of technologies that can have a material impact on its competitive advantage are core technology; all others are peripheral. Of course in a dynamic world, peripheral technologies can become tomorrow's core technologies and vice versa (Burgelman and Rosenbloom, 1989).

$\circ$ depth of technology strategy encompasses the number of technological options the firm has available. The depth of a firm's technology strategy is determined to a significant extent by the intensity of its resource expenditures. Investment in technological resources is positively related to technical output (Mansfield, 1981). Expenditure on internal R\&D has a strong relationship to increased profitability (Capon et al, 1990).

- organizational fit encompasses administrative and cultural factors of the firm. Patterns of technical communication throughout the construction organization are important determinants to the quality of organizational fit. From the Burgelman and Rosenbloom (1989) evolutionary point of view, organizational context serves as an internal selection mechanism affecting the strategic management of the firm. Burgelman and Sayles (1986) work suggests that reward systems may provide potential measures of one aspect of the organizational context of technology strategy.

\subsection{Link Between Technology Strategy and Performance}

The background literature contains examples of relationships between technologyrelated inputs and competitive performance. The Miles and Snow (1978) typologies include a technology-based component. The four basic patterns of strategy that emerged however, are principally based on a descriptive analysis of how an organization changes its products or markets. While each of these cases is of interest in their own right, no linkages are apparent corresponding to the recently unified concept of technology strategy which comprises a diverse range of inputs and competitive performance. 


\section{FORMULATING TECHNOLOGY STRATEGY FOR AUTOMATION}

Selecting a firm's approach to a specific technology requires consideration of each element: positioning, sourcing, scope, depth, and organizational fit. This section describes a process of formulating technology strategy, primarily using examples of CAD applications in construction, coordinate positioning technology and highly mechanized falsework/formwork systems. By considering each of the elements for several candidate technologies, managers can formulate a technology strategy that best fits the capabilities and culture of a firm and creates substantial competitive advantages.

\subsection{Competitive Positioning}

Automation technology can provide several types of competitive advantages. Examples include: offering new products in new markets, developing distinctive or unique competence, serving a niche market, reducing project durations, and decreasing life cycle cost (Tatum, 1989a). Analysis of customer needs, types of contracts, and external influences on markets provides a basis to select a type of competitive advantage for a firm. This analysis can identify the competitive advantages that are desirable for the market conditions and feasible for the specific firm, along with the types of technologies that can provide this advantage.

Using CAD technology at the construction site to increase the effectiveness of construction engineering activities can create competitive advantages based on decreased project duration and decreased construction cost. For example, Construction Engineers can use $\mathrm{CAD}$ at the site to automate existing processes or to create new processes and products that allow more effective support of field engineering operations (Mahoney et al, 1990). Examples of using $\mathrm{CAD}$ to automate existing processes include planning survey control and layout, planning construction sequences and methods, and coordinating subcontractors. In each case, $\mathrm{CAD}$ drawings allow more complete analysis and improved communication of plans. Examples of using CAD for new processes and products include visualizing complex configurations, analyzing requirements for construction equipment, and detailing portions of the structure to allow the use of specialized construction methods. Each of these applications results in more complete technical information for field operations.

Automated positioning technology can provide advantages based on offering new products in new markets or developing distinctive competencies. For example, applications of automated positioning in the grading and paving industry could allow the accurate preparation of pavement subgrade and base, and permit placing the asphalt or concrete wearing surface to comply with more stringent tolerances for pavement location and surface finish. The high cost of concrete grinding and set-up labor for traditional equipment encourages use of this type of positioning technology through to decrease total construction cost.

Unique or distinctive competence can also be achieved within the concrete highway bridge construction sector through the development of mechanized falsework and formwork systems that address the industry drivers of labor cost and operational safety. For example, a series of fabricated steel trusses that efficiently combine the traditional functions of falsework and formwork and allow construction of a new double-deck freeway level to proceed over an existing busy highway provides clear competitive positioning advantages for its owner - especially when the investment in this more advanced construction mechanization is carried out during the inception of this type of continuing work. The entire system could also include prefabricated internal formwork and incorporate concrete placing and finishing 
equipment - all enclosed by debris panels to allow construction to proceed safely during normal working hours. When future project phases of a similar nature are bid, the strategic early investment in labor-saving construction automation/mechanization can provide unmistakably clear benefits.

\subsection{Sourcing of Technology}

Several options are available to acquire new technology for automation. These include: interact with a lead developer, conduct internal development, improve processes for repeated operations, drive technology development on specific projects, and interact with owners and operators (Tatum, 1989a). These approaches involve plans and commitment of resources to acquire a new technology and effectively use it. The most critical resources are not always financial - commitment of time by operations managers or field staff may be more important for success than funds.

Several different approaches for acquiring CAD to support construction illustrate the breadth of options available (Mahoney et al, 1990). The president of one firm bought hardware and software for $\mathrm{CAD}$, put it on the site of a major projects, and instructed the staff to find productive uses. Illustrating a completely opposite approach, a field engineer in another firm used his personal computer and software to demonstrate beneficial applications of $\mathrm{CAD}$ in preparing lift drawings and planning concrete placements. In other firms, the home office engineering staff or consultants took the actions needed to acquire the technology, implement it, and demonstrate the advantages.

Throughout the development of the mechanized falsework system for double-decking existing freeways, the principal of one bridge construction firm maintained close personal involvement. (His employees jokingly referred to him as their "chief falsework designer".) Following the initial conceptual design carried out in-house, a number of external specialists were called upon to complete the detailed engineering and fabrication functions.

Co-operative interaction with the public facility owner through a value engineering scheme proved central in encouraging innovation from the construction community in developing alternative designs. The magnitude of one $\$ 52$ million project encouraged the development of advanced falsework and formwork systems with almost 50 complete repetitions of the span-by-span construction of the $67^{\prime}(20.4 \mathrm{~m})$ wide deck. The motivation to improve the processes for repeated operations enabled continual incremental improvements. This also placed the contractor in a commanding position for future similar contracts.

In an example of sourcing implicit technology (represented by knowledge or skills embodied in people), another construction firm took over the key staff from a retiring specialist subcontractor when they made the strategic decision to merge piledriving into their own existing structural concrete construction capabilities. Experienced (and committed) skilled labor was therefore smoothly integrated into their own organization, with the benefit of having witnessed the skills and work attitudes of the potential employees over a decade of close industry involvement.

\subsection{Scope of Technology Strategy}

Applications of construction automation provide examples of variations in the scope of construction technology. Although there are many examples of beneficial applications of CAD to support construction engineering, it remains a peripheral technology compared with more traditional equipment and tools used in construction operations. Computer applications to support project planning, materials management, and performance monitoring are additional 
examples of peripheral technologies. However, several types of construction firms illustrate the use of advanced equipment and early construction automation as core technologies. These include laser positioning for fine grading (Tatum and Funke, 1988), partially automated devices for underwater bolting (Stewart and Tatum, 1988), specialized equipment for transporting and setting heavy equipment (Tatum, 1983), and automated welding machines for large plate work and high pressure piping. For each of these technologies, several firms have developed a core competence and applied the technology to perform work that others cannot perform or to gain substantial schedule and cost advantages.

Another example reflects the potential benefits gained through the scope of abilities embodied in the firm's people or through strategic alliances with external professionals. Strong in-house engineering skills, for instance, can reveal opportunities available through optimizing falsework materials, and through redesigns under the province of value engineering.

One highway construction firm has demonstrated a successful integration of site project control through the on-site application of computer project programming and job costing. The progress of job sectors or individual operations can be tracked almost daily to allow potential problems to be highlighted and corrections applied, before they significantly impact project success.

\subsection{Depth of Technology Strategy}

Construction applications of CAD illustrated variations in depth of technology strategy. The commitment and level of resources ranged from a major investment in multiple high-end workstations for one project, to purchase of software compatible with the low-end personal computers designated for administrative use at the site (Mahoney et al, 1990). The core technologies identified above illustrate the increased depth necessary to achieve distinctive competence.

Infrastructure construction firms benefit through their ability to provide prompt and effective technical response to site problems. Two differing approaches characterize successful performance in this area:

- technically qualified and experienced supervision operating independently at the construction site, and;

- $\quad$ production-oriented and trade experienced supervision based on site - with technical expertise, e.g. engineering - based in home office, but allocated to specific projects and readily accessible by phone, fax, or radio (potential for video communication for future). In this manner, the depth of professional skills based at head office can be effectively spread over a number of projects - thereby lowering job overheads.

Expenditure on R\&D in the formal sense is minimal in the highway infrastructure firms surveyed. However, in a similar way that Nam and Tatum $(1992, \mathrm{p} 522)$ have reported in their evaluation of the source of key technical ideas, a substantial number of innovations and enhanced project automation or mechanization comes from informal R\&D activities described "as a clever collection, transfer, or improvement of already-known technologies". The innovative investment in the trussed falsework system for double decking freeways is an example of more advanced construction process hardware developed in this fashion.

\subsection{Organizational Fit}

Several examples of construction innovation from heavy and building construction illustrate the importance of the organization in creating the environment necessary for technical change (Tatum, 1989b, Nam et al, 1991). Key actions in organizing for innovation 
include establishing supportive policies and priorities, maintaining flexibility in grouping and providing technical resources, facilitating intra- and interorganizational coordination, and staffing to satisfy specific requirements for key positions (Tatum, 1989b). Further, linking personal reward structures to the technological objectives of the firm serves as a meaningful signal to employees (Burgelman and Sayles, 1986).

Examples of CAD applications on construction sites illustrate the types of organizational environments that foster the adoption of new technology. These included strong support by senior managers, established technical excellence in the firm, and willingness to allow experimentation with new approaches. These innovative organizations lacked rigid structure and position descriptions, fostered individual initiative and experimentation, and included several types of champions (Mahoney et al, 1990).

More successful infrastructure construction companies demonstrate a number of consistent organizational characteristics including: strong personal involvement by principals, an established core of technical competence in the firm (either at the home office or on site), personal and group reward structures that reflect productivity and safety improvements, and personal communication networks unimpeded by either project location or organizational responsibility.

Since labor is the largest single cost component of highway bridge construction, a technology strategy to maximize productive output per employee through construction automation and mechanization is of paramount importance to enhance company performance in this competitive environment.

\section{CONCLUSIONS}

Technology strategy guides the construction firm's approach to the consideration and implementation of technologies within the context of the overall competitive and business goals of the organization. This paper has identified and summarized elements of technology strategy synthesized from the background literature. It then provided examples of its application to the integration of CAD, co-ordinate positioning, and site mechanization in construction activities.

The five key dimensions to be considered in formulating an appropriate technology strategy are: competitive positioning, sourcing of technology, scope of technology, depth of technology strategy and organizational fit. Through selecting a strategy that best suits the existing capabilities of a firm, and addressing the construction sector market forces, managers can be better prepared to face the increasingly competitive environment in which they operate. Formulating a technology strategy cannot guarantee market success. But the diligent application and implementation of the technology strategy concept can provide the foundation for the creation of substantial competitive advantage.

\section{REFERENCES}

- Adler, Paul S, "Technology Strategy: A Guide to the Literatures", in Research on Technological Innovation, Management and Policy, Rosenbloom, Richard S. and Burgelman, Robert A. (eds), Vol 4, JAI Press, Greenwich, CT, 1989, pp25-151.

- $\quad$ Ansoff, H.Igor and Stewart, John M., "Strategies for a Technology-Based Business" in Harvard Business Review, Nov/Dec, 1967, pp71-80.

- Burgelman, Robert A. and Rosenbloom, Richard S., "Technology Strategy: An Evolutionary 
Process Perspective" in Rosenbloom, R.S. and Burgelman, R.A., (eds), Research on Technological Innovation, Management and Policy, Vol 4, Greenwich, CT, JAI Press Inc, 1989.

- Burgelman, Robert A. and Sayles, Leonard R., Inside Corporate Innovation: Strategy, Structure, and Management Skills, The Free Press, New York, NY, 1986.

- $\quad$ Chandler, A.D., Strategy and Structure, MIT Press, Cambridge, MA, 1962.

- $\quad$ Freeman, Christopher, The Economics of Industrial Innovation, 2nd ed., MIT Press, Cambridge MA, 1982.

- $\quad$ Glueck, W.F., Strategic Management and Business Policy, McGraw-Hill, New York, 1980.

- $\quad$ Mahoney, John J., C. B. Tatum, and Kenji Kishi, "Construction Site Applications of CAD," Technical Report No. 36, Center for Integrated Facility Engineering, Stanford University, Stanford, California, October, 1990.

- Maidique, M.A. and Patch, P., "Corporate Strategy and Technological Policy", in Tushman, M.L. and Moore, W.L. (eds), Readings in the Management of Innovation, 2nd ed, Ballinger, 1988, pp236-248.

- Malekzadeh, Ali R; Bickford, Deborah J. and Spital, Francis C., "Integrating Environment, Competitive Strategy, and Structure with Technology Strategy: The Strategic Configurations", Academy of Management 49th Annual Meeting, Washington DC, August, 1989.

- Mansfield, Edwin, "Composition of R\&D Expenditures: Relationship to Size of Firm, Concentration and Innovative Output", The Review of Economics and Statistics, Vol 18, Iss 4, November 1981, pp610-615.

- Miles, Raymond E. and Snow, Charles C., Organizational Strategy, Structure and Process, McGraw-Hill, New York, 1978.

- Nam, C. H., J. G. Gasiorowski, and C. B. Tatum, "Microlevel Study of Integration in High-Strength Concrete Innovation," Journal of Construction Engineering and Management, ASCE, Vol. 117, No. 2, June, 1991, pp294-309.

- Nam, C. H., and C. B. Tatum, "Strategies for Technology Push: Lessons from Construction Innovations," Journal of Construction Engineering and Management, ASCE, Vol. 118, No. 3, September, 1992, pp507-524.

- Porter, Michael E., Competitive Advantage: Creating and Sustaining Superior Performance, Free Press, New York, NY, 1985.

- $\quad$ Rosenberg, N.; Ince, P., Skog, K. and Plantinga, A., "Understanding the Adoption of New Technology in the Forest Products Industry, Forest Products Journal, Vol 40, Iss 10, October, 1990, pp15-22.

- Stewart, William S., and C. B. Tatum, "Segmental Placement of the Renton Outfall: A Construction Innovation," Journal of Construction Engineering and Management, ASCE, Vol. 114, No. 3, September, 1988, pp390-407.

- $\quad$ Tatum, C. B., "Heavy Rigging for Nuclear Projects," Journal of Construction Engineering and Management, ASCE, Vol. 109, No. 1, March, 1983, pp48-60.

- Tatum, C. B., "Classification System for Construction Technology," Journal of Construction Engineering and Management, ASCE, Vol. 114, No. 3, September, 1988, pp344-363.

- Tatum, C. B., "Design and Construction Automation: Competitive Advantages and Management Challenges," Proceedings of the 6th International Symposium on Automation and Robotics in Construction, San Francisco, June 6-8, 1989a, pp332-339.

- Tatum, C. B., "Organizing to Increase Innovation in the Construction Firm, Journal of Construction Engineering and Management, ASCE, Vol. 115, No. 4, December, 1989b, pp602-617.

- Tatum, C. B. and A. T. Funke, "Partially-Automated Grading: A Construction Process Innovation," Journal of Construction Engineering and Management, ASCE, Vol. 114, No. 1, March, 1988, pp19-35. 